\title{
O3 IMPROVING INJURY PREVENTION RESEARCH THROUGH PATIENT AND PUBLIC INVOLVEMENT-TOWARDS WORKING IN PARTNERSHIP
}

doi:10.1136/injuryprev-2012-040590p.3

1,2J Stewart, ${ }^{1} \mathrm{R}$ Clacy, ${ }^{1} \mathrm{P}$ Benford, ${ }^{1} \mathrm{~J}$ Ablewhite, ${ }^{1} \mathrm{D}$ Kendrick, ${ }^{1}$ on behalf of the Keeping Children Safe at Home programme team. 'University of Nottingham, England; ${ }^{2}$ Nottinghamshire Healthcare NHS Trust, England

Background Lay involvement in research has been proved to have advantages both at a national and local level. Hence major research funders require evidence of Patient and Public Involvement (PPI) in development of proposals and the conduct of research.

Aims The aims are to describe how PPI is part of the Keeping Children Safe at Home (KCS) research programme and how this has made a difference to the research.

Methods A PPI representative has worked with researchers since the development of the funding application for the KCS programme. She contributes to research management meetings and works with researchers at all stages of the research from developing research tools to collection and analysis of data and report writing. Outcome The outcome has been positive. Researchers welcome the different perspective to research bought by PPI. Involvement in the development of invitation letters, information leaflets and questionnaires has made them more understandable for potential participants. Parents responded more positively to the PPI representative than to researchers during piloting of materials resulting in higher questionnaire completion rates. The PPI representative has also collected data both in parent's homes and in a community setting, and contributed to analysis of parent interview data. In all these areas, issues from the parent perspective that researchers may not have thought about have been identified.

Contribution to the Field This demonstrates the benefits of partnership working between PPI representatives and researchers dedicated to injury prevention and highlights the important contribution PPI can make in the field of injury prevention. 